\title{
Chaotic time series prediction with deep belief networks: an empirical evaluation
}

\author{
Ta Ngoc Huy Nam, Duong Tuan Anh*
}

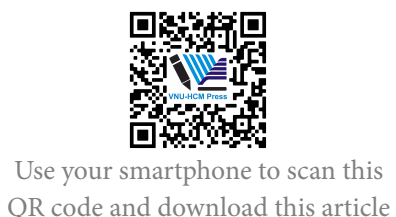

QR code and download this article

\begin{abstract}
Chaotic time series are widespread in several real world areas such as finance, environment, meteorology, traffic flow, weather. A chaotic time series is considered as generated from the deterministic dynamics of a nonlinear system. The chaotic system is sensitive to initial conditions; points that are arbitrarily close initially become exponentially further apart with progressing time. Therefore, it is challenging to make accurate prediction in chaotic time series. The prediction using conventional statistical techniques, k-nearest-nearest neighbors algorithm, Multi-Layer-Perceptron (MPL) neural networks, Recurrent Neural Networks, Radial-Basis-Function (RBF) Networks and Support Vector Machines, do not give reliable prediction results for chaotic time series. In this paper, we investigate the use of a deep learning method, Deep Belief Network (DBN), combined with chaos theory to forecast chaotic time series. DBN should be used to forecast chaotic time series. First, the chaotic time series are analyzed by calculating the largest Lyapunov exponent, reconstructing the time series by phase-space reconstruction and determining the best embedding dimension and the best delay time. When the forecasting model is constructed, the deep belief network is used to feature learning and the neural network is used for prediction. We also compare the DBN -based method to RBF network-based method, which is the state-of-the-art method for forecasting chaotic time series. The predictive performance of the two models is examined using mean absolute error (MAE), mean squared error (MSE) and mean absolute percentage error (MAPE). Experimental results on several synthetic and real world chaotic datasets revealed that the DBN model is applicable to the prediction of chaotic time series since it achieves better performance than RBF network.

Key words: Deep Belief Network, Restricted Boltzmann Machine, chaotic time series, RBF network, forecasting
\end{abstract}

Ho Chi Minh City University of Technology, VNU-HCM

\section{Correspondence}

Duong Tuan Anh, Ho Chi Minh City University of Technology, VNU-HCM

Email: dtanhcse@gmail.com

History

- Received: 28-8-2019

- Accepted: 26-9-2019

- Published: 04-12-2020

DOI : 10.32508/stdjet.v3iSI1.571

\section{Check for updates}

\section{Copyright}

(c) VNU-HCM Press. This is an openaccess article distributed under the terms of the Creative Commons Attribution 4.0 International license.

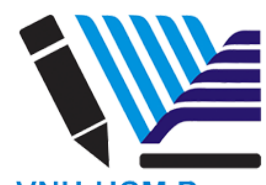

VNU-HCM Press

\section{INTRODUCTION}

Time series in several real world areas such as finance, environment, meteorology, and weather are characterized as chaotic in nature. A chaotic time series is generated from the deterministic dynamics of a nonlinear system $\left({ }^{1,2}\right)$. The chaotic system is sensitive to initial conditions; points that are arbitrarily close initially become exponentially further apart with progressing time. Therefore, it is challenging to make accurate prediction in chaotic time series. The prediction using conventional statistical techniques, k-nearest-nearest neighbors algorithm, Multi-LayerPerceptron (MLP) neural networks, Recurrent Neural Networks, Radial-Basis-Function (RBF) Networks and Support Vector Machines (SVMs), do not give reliable prediction results for chaotic time series.

Deep learning models, such as Deep Belief Networks (DBNs), have recently attracted the interest of many researchers in some applications on big data analysis. DBN is generative neural network model with many hidden layers, introduced by Hinton et al. ${ }^{3}$ along with a greedy layer-wise learning algorithm. The building block of a DBN is a probabilistic model called Restricted Boltzmann Machine (RBM). DBNs and restricted Boltzmann machines (RBMs) have already been applied successfully to solve many problems, such as classification, dimensionality reduction and image processing.

There have been several research works of applying DBNs to predict time series data in finance $(4,5)$, meteorology $\left({ }^{6,7}\right)$, and industry $\left({ }^{8}\right)$. However, so far there have been very few works on applying DBNs in forecasting chaotic time series. Kuremoto et al. in 2014 [6] studied the application of a DBN which composes RBMs and multi-layer perceptron (MLP) to predict chaotic time series data. The hyperparameters of the deep network were determined by particle swarm optimization (PSO) algorithm. Despite of the simple and effective structure for the proposed DBN, there exist three weaknesses in this paper. First, the paper does not make clear that the DBN model is combined with chaos theory in dealing with chaotic time series prediction. Second, the 
work has tested DBN model over only two synthetic chaotic time series datasets: Lorenz and Henon Map. The lack of testing the proposed model with real world chaotic time series datasets cannot validate the high performance of DBN model in practical applications of chaotic time series prediction. Third, the work compared DBN model with only MLP model, a simple form of shallow neural networks.

In this work, we present and evaluate extensively a method of chaotic time series prediction using the DBN model which has the same structure as given in the paper ${ }^{9}$. However, there are three focus points in our work which makes it different from the previous work by Kuremoto et al. in 2014 .

i) We combine the DBN model with the chaos theory, namely phase space reconstruction, in dealing with chaotic time series prediction.

ii) We compare the performance of DBN model to that of Radial Basis Function (RBF) network, a special kind of shallow neural networks which can bring out better forecasting precision than MLP neural network in chaotic time series prediction ${ }^{10}$.

iii) To verify the effectiveness of DBN, we experiment the performance of DBN over several benchmark chaotic time series datasets. In experiment, we use three synthetic time series datasets: Lorenz, Mackey-Class, Rossler and four real world time series datasets: Sunspots and some financial/economic datasets. The predictive performance of the two models is examined using mean absolute error (MAE), mean square error (MSE) and mean absolute percentage error (MAPE). Experimental results through three evaluation criteria revealed that DBN outperforms RBF network in most of the datasets.

The remainder of the paper is organized as follows. Section 2 provides some basic backgrounds about DBN and chaos theory. In Section 3, the method using DBN for forecasting chaotic time series is introduced. Section 4 reports the experiments to compare the prediction accuracy of the DBN method to that of the RBF network model. Finally, section 5 gives some conclusions and future work.

\section{BACKGROUND AND RELATED WORKS}

\section{Deep Belief Network}

Restricted Boltzmann Machines (RBMs) are often used to construct deeper models such as DBN. RBM is a kind of stochastic artificial neural network with two connected layers: a layer of binary visible units ( $v$, whose states are observed) and a layer of binary hidden units ( $h$, whose states cannot be observed). The hidden units act as latent variables (features) that allow the RBM to model probability distribution over state vectors (see Figure 1). The hidden units are conditionally independent given visible units. Given an energy function $E(v, h)$ on the whole set of visible and hidden units, the joint probability is given by:

$$
p(v, h)=\frac{e^{-E(v, h)}}{Z}
$$

where $Z$ is a normalization partition function, which is obtained by summing up the energy of all possible $(\boldsymbol{v}, \boldsymbol{h})$ configurations.

$$
Z=\sum_{v, h} e^{-E(v, h)}
$$

For the binary units $h_{i} \in\{0,1\}$ and $v_{i} \in\{0,1\}$, the energy function of the whole configuration is:

$$
\begin{aligned}
& E(v, h)=-c v^{\mathbf{T}}-b h^{\mathbf{T}}-h W v^{\mathbf{T}} \\
& =-\sum_{k=1}^{K} c_{k} v_{k}-\sum_{j=1}^{J} b_{j} h_{j}-\sum_{j=1}^{J} \sum_{k=1}^{K} W_{j k} v_{k} h_{j}
\end{aligned}
$$

where $\boldsymbol{W}$ is $J \times K$ matrix of RBM weights, $\boldsymbol{c}=\left[c_{1}\right.$, $\left.c_{2}, \ldots, c_{K}\right]$ is the bias of the visible units and $\boldsymbol{b}=\left[b_{1}\right.$, $\left.b_{2}, \ldots, b_{J}\right]$ the bias of the hidden units. The marginal distribution over $\boldsymbol{v}$ is:

$$
p(v)=\sum_{h} p(v, h)
$$

The posterior probability of one layer given the other is easy to compute by the two following equations:

$$
p(h, v)=\prod_{j} p\left(h_{j}=1 \mid v\right)
$$

where $p\left(h_{j}=1 \mid v\right)=\sigma\left(b_{j}+\sum_{k} W_{j k} v_{k}\right)$

$$
p(v, h)=\prod_{k} p\left(v_{k}=1 \mid h\right)
$$

where $p\left(v_{k}=1 \mid h\right)=\sigma\left(c_{k}+\sum_{j} W_{j k} h_{j}\right)$

Notice that $\sigma$ is the sigmoid function. Inference of hidden factor $\boldsymbol{h}$ given the observed $\boldsymbol{v}$ can be done because $\boldsymbol{h}$ is conditionally independent given $\boldsymbol{v}$.

A DBN is a generative model with an input layer and an output layer, separated by $l$ layers of hidden stochastic units. This multilayer neural network can be efficiently trained by composing RBMs in such a way that the feature activations of one layer are used as the training data for the next layer.

An energy-based model of RBMs can be trained by performing gradient ascent on the log-likelihood of the training data with respect to the RBMs parameters. This gradient is difficult to compute analytically. Markov Chain Monte Carlo methods are wellsuited for RBMs. One iteration of the Markov Chain works well and corresponding to the following sampling procedure:

$$
v_{0} \stackrel{p\left(h_{0} \mid v_{0}\right)}{\longrightarrow} h_{0} \stackrel{p\left(v_{1} \mid h_{1}\right)}{\longrightarrow} v_{1} \stackrel{p\left(h_{1} \mid v_{1}\right)}{\longrightarrow} h_{1}
$$




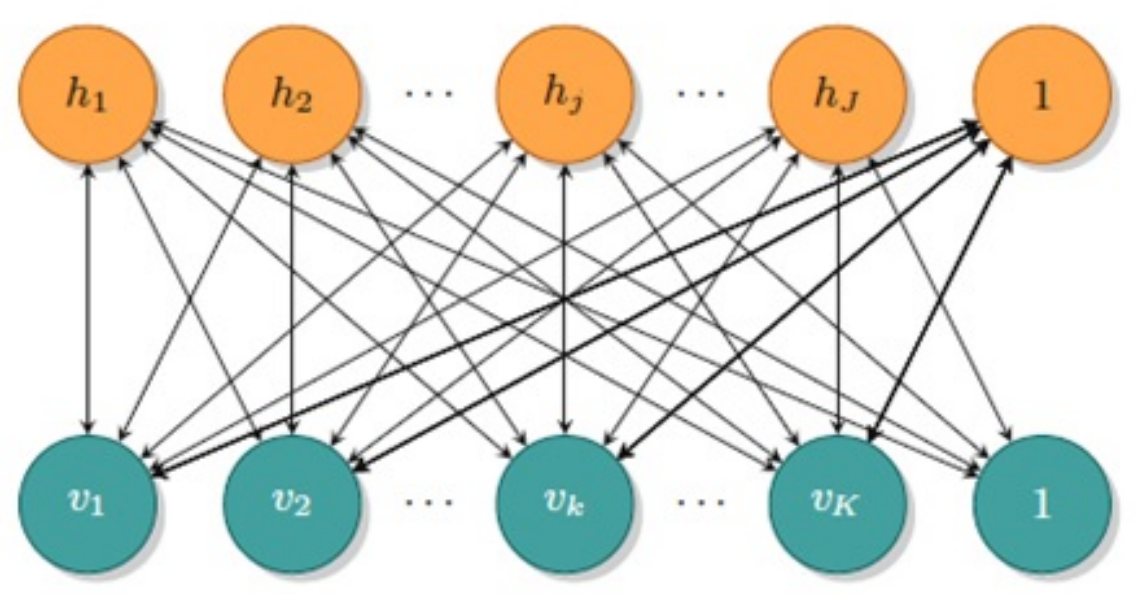

Figure 1: Restricted Boltzmann Machine (RBM)

where the sampling operations are schematically described. Rough estimation of the gradient using the above procedure is denoted by CD-k, where CD-k represents the Contrastive Divergence algorithm ${ }^{3}$ for performing $k$ iterations of the Markov Chain up to $v_{k}$.

\section{Chaos Theory}

Given a univariate time series $x_{t}$, where $t=1,2, \ldots$, $N$, the phase space can be reconstructed using the method of delays ${ }^{1}$. The essence in this method is that the evolution of any single variable of a system is determined by the other variables with which it interacts. Information about the relevant variables is thus implicitly contained in the history of any single variable. On the basis of this idea, an equivalent phase space can be constructed by assigning an element of the time series $x_{t}$ and its successive delays as coordinates of a new vector.

$$
X_{t}=\left\{x_{t}, x_{t+\tau}, x_{t+2 \tau}, \ldots, x_{t+(m-1) \tau}\right\}
$$

where $X_{t}$ are the points of phase space, $t$ is the delay time and $m$ is embedding dimension. The dimension $m$ of the reconstructed phase space is considered as the sufficient dimension for recovering the object without distorting any of its topological properties, thus it may be different from the true dimension of the space where this object lies. Both the $t$ and $m$ parameters must be determined from the time series.

To determine a reasonable time delayt, we can apply the mutual information method proposed by Fraser and Swinney ${ }^{11}$. To determine the minimum sufficient embedding dimension $m$ we can apply the false nearest neighbor method proposed by Kennel et al. ${ }^{2}$.
To check whether a time series is chaotic or not, one needs to calculate the maximal Lyapunov exponent. Rosenstein et al. ${ }^{12}$ proposed a method to calculate the largest Lyapunov exponent from an observed time series.

\section{Related Work}

In our previous work ${ }^{10}$, we proposed an efficient method of chaotic time series prediction using Radial Basis Function (RBF) network, a special kind of shallow neural networks.

The RBF network is characterized by a set of inputs and a set of outputs. Between the inputs and outputs there is a layer of hidden units, each of which implements a radial basis function. Various functions have been tested as activation function for RBF network. Gaussian function is often used to activate the hidden layer. The nodes in the hidden layer operate on the distance from an applied input vector to an internal parameter vector, called a center. The output layer implements a weighted sum of hidden-unit outputs. The mapping function is given by:

$$
p_{j}(X)=\sum_{i=1}^{n} w_{i j} \phi_{i}\left(\left\|X-c_{i}\right\|\right)
$$

for $j=1,2, \ldots, l$, where $X$ is the input $m$-dimensional vector, $p_{j}(X)$ is the output of the $j$-th unit, $w_{i j}$ are the output weight from the $i$-th hidden unit to the $j$-th output unit, $n$ is the number of hidden units, $\phi_{i}$ is the $i$-th radial basis function at the $i$-th hidden node. If Gaussian function is used as radial basis function, $\phi_{i}$ is defined as follows.

$$
\phi_{i}\left(\left\|X-c_{i}\right\|\right)=\exp \left(-\frac{1}{2}\left(\frac{\left\|X-c_{i}\right\|}{\sigma_{i}}\right)^{2}\right)
$$


where $c_{i}$ is the center and $\sigma_{i}$ is the width of the $i$-th hidden unit, respectively.

RBF network is trained using unsupervised and supervised learning methods. The unsupervised method is implemented between input to hidden layers and supervised method is implemented from hidden to output layer. Clustering algorithms are capable of finding cluster centers that best represents the distribution of data in the first stage of the training. There are two alternative heuristics for finding width factors $\left({ }^{13}\right)$

$\mathrm{In}^{10}$, we compared the performance of RBF network to that of MLP network on several real and synthetic datasets of chaotic time series. Experimental results revealed that RBF network with phase space reconstruction outperforms MLP networks in chaotic time series prediction.

\section{DEEP LEARNING METHOD FOR CHAOTIC TIME SERIES PREDICTION: DBN}

Inspired with the work by Kumemoto et al. ${ }^{9}$, we use the DBN model which composes one or two RBMs and MLP to forecast chaotic time series. The DBN model is used for feature learning and the MLP is for prediction. The forecasting DBN model is described in Figure 2.

As for the number of input nodes (at the first visible layer of $\mathrm{RBM}(\mathrm{s})$ ) of $\mathrm{DBN}$, we determine this parameter by using the embedding dimension $(m)$ that we obtained when applying the phrase-space reconstruction method for each chaotic dataset. Each input node has one external input which represents the elements of $X_{t}$, i.e., $x_{t}, x_{t+\tau}, x_{t+2 \tau}, \ldots, x_{t+(m-1) \tau}$. That means we combine DBN model with chaos theory in chaotic time series prediction.

As for the activation function used in DBN, we use RELU function which is described by the following formula:

$$
\operatorname{RELU}(x)=\left\{\begin{array}{l}
0 \text { if } x<0 \\
x \text { if } x \geq 0
\end{array}\right.
$$

The training algorithm for our proposed DBN consists of two stages: an unsupervised learning and a supervised learning.

The unsupervised learning stage is the Contrastive Divergence (CD) algorithm ${ }^{3}$ used for training the $\mathrm{RBM}(\mathrm{s})$. The CD algorithm progresses on a layer-bylayer basis. First, a RBM is trained directly on the input data. Hence, the neurons in the hidden layer of the RBM can capture the important features of the input data. The activations of the trained features are then used as "input data" to train a second RBM.
The supervised learning stage is the back-propagation algorithm used for training the MLP.

\section{EXPERIMENTAL EVALUATION}

In this experiment, we compare the DBN method for chaotic time series forecasting to the method using RBF network. We implemented the DBN forecasting method with Tensorflow framework (using Python language ${ }^{14}$ and the RBF method with Microsoft Visual C\#, . Net framework 4.5 and conducted the experiments on a Core i5 $2.4 \mathrm{GHz}$, RAM 8GB PC.

In this study, the mean absolute error (MAE), the mean squared error (MSE) and the mean absolute percentage error (MAPE) are used as evaluation criteria. The formula for MAE, MSE and MAPE are given as follows:

$$
\begin{aligned}
& M A E=\frac{1}{n} \sum_{t=1}^{n}\left|\widehat{y}_{t}-y_{t}\right| \\
& M S E=\frac{1}{n} \sum_{t=1}^{n}\left(\widehat{y}_{t}-y_{t}\right)^{2} \\
& M A P E=\frac{1}{n} \sum_{t=1}^{n} \frac{\left|\widehat{y}_{t}-y_{t}\right|}{y_{t}}
\end{aligned}
$$

where $n$ is the number of observations, $y_{t}$ is the actual value in time period $t$, and $\hat{y}_{t}$ is the forecast value for time period $t$.

\section{Datasets and Parameter Setting}

The main purpose of this study is to evaluate the performance of DBN in forecasting not only on synthetic but also real world chaotic time series. This follows the tradition of evaluating the proposed methods in chaotic time series prediction. Here, the tested datasets consist of 3 synthetic chaotic time series datasets and 4 real world chaotic time series datasets. All these datasets are commonly-used by the research community in chaotic time series prediction. They are described as follows.

1. This dataset is derived from the Lorenz system, given by the three differential equations:

$$
\left\{\begin{array}{c}
\frac{d x}{d t}=a(y-x) \\
\frac{d z}{d t}=x y-c z \\
\frac{d y}{d t}=x(b-z)-y
\end{array}\right.
$$

where, $a=10, b=28$, and $c=8 / 3$. This time series consists of 1000 data points.

2. This dataset is derived from the Mackey-Glass system, given by the following differential equation:

$$
\frac{d x(t)}{d t}=\frac{a x(t-\tau)}{1+x^{c}(t-\tau)}-b x(t)
$$

where $a=0.2, b=0.1, c=10, t=17$ and $x_{0}=1.2$. This time series consists of 1001 data points. 


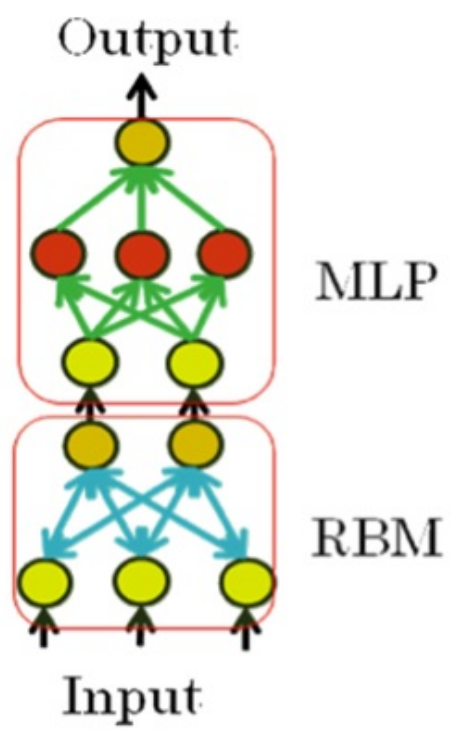

(a) A DBN with a RBM and a MLP

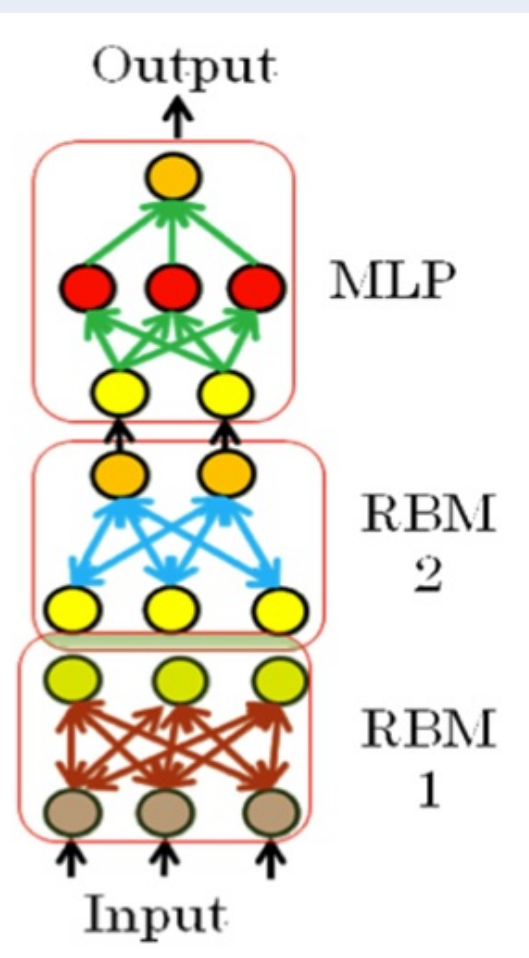

(b) A DBN with 2 RBMs and a MLP

Figure 2: $A$ DBN with $\operatorname{RBM}(\mathrm{s})$ and $\operatorname{MLP}\left({ }^{9}\right)$

3. This dataset is derived from the Rossler system, given by the three differential equations:

$$
\left\{\begin{array}{c}
\frac{d x}{d t}=-z-y \\
\frac{d z}{d t}=b+z *(x-c) \\
\frac{d y}{d t}=x+a * y
\end{array}\right.
$$

where $a=0.15, b=0.2$ and $c=10$. This time series consists of 8192 data points.

4. Monthly sunspot numbers from January of 1749 to March of 1977. (This dataset from the web site: http:/ /sidc.oma.be).This time series is in the field of astronomy and is a widely-used benchmark dataset in evaluation of several proposed methods for chaotic time series prediction. It consists of 305 data points.

5. Monthly CPI (Consumer Price Index) in Spain from January of 1960 to June of 2005. (This dataset from: http ://www.bde.es/bde/en/). This time series consists of 535 data points.

6. Monthly exchange rates US dollar/British Pound (USD/GBP) from January 1981 to July of 2005. (This dataset from the web site: http://www.bde.es/bde/en/ ). This time series consists of 295 data points.

7. Daily close prices of IBM stock from June of 1959 to June of 1960. (This dataset from the web site: http:/ /datamarket.com/data/set/). This time series consists of 255 data points.

Figure 3 shows the plots of the three synthetic datasets. Figure 4 shows the plots of the four real world datasets.

With four real world datasets (Sunspots, CPI, USD/GBP, IBM) we use Lyapunov exponent to check whether each of time series is chaotic or not. The test shows that all four datasets possess the chaotic characteristics.

In this work, we estimate the embedding dimension and compute Lyapunov exponents by using the tseriesChaos package in the R software (website: https://C RAN.R-project.org/package $=$ tseriesChaos).

In the experiment, we use RBF network in two versions: RBF with chaos theory (denoted as RBF-2) and RBF without chaos theory (denoted as RBF-1). For RBF-2, we have to determine the embedding dimen- 


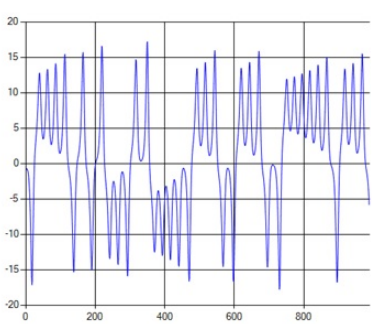

(a)

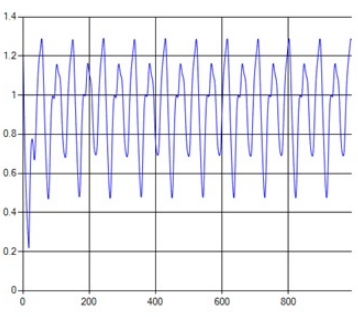

(b)

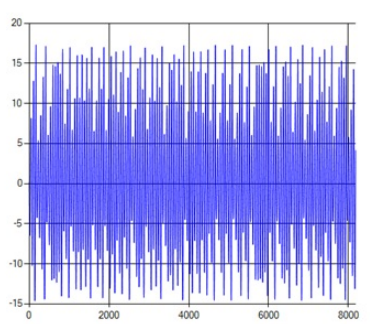

(c)

Figure 3: Three datasets: (a) Lorenz; (b) Mackey-Glass; (c) Rossler

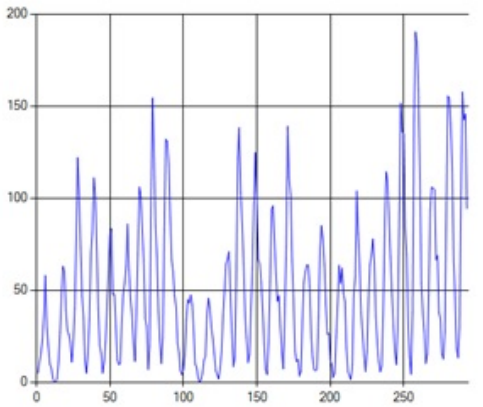

(a)

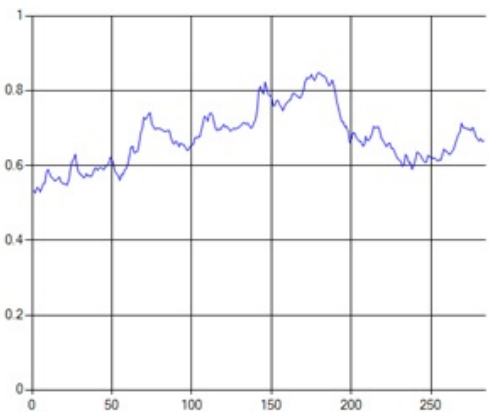

(c)

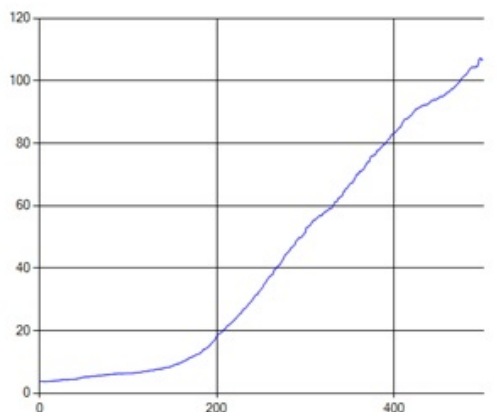

(b)

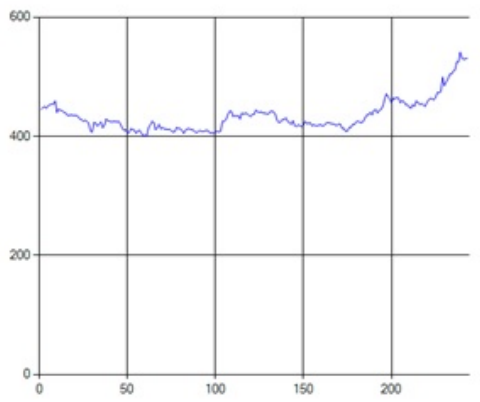

(d)

Figure 4: Four datasets (a) Sunspots; (b) CPI; (c) USD/GBP; (d) IBM Stock prices

sion $m$ and the time delay $t$ for each chaotic time series.

For all datasets, the RBF has the maximum number of learning iterations set to 1000 . The parameter values for two versions of RBF network with all datasets are reported in Table 1 . In Table $1, \eta_{3}$ is the learning rate for output weights, $\eta_{2}$ is the learning rate for centers and $\eta_{1}$ is the learning rate for width factors.

The parameter values of DBN model for all datasets are reported in Table 2. As suggested in the paper ${ }^{9}$, we set the number of RBMs in DBN model to 1 or 2. Except for Sunspots dataset, we use only one RBM in DBN for all the datasets and use two RBMs only for the Sunspots dataset. As for the number of input nodes (at the first visible layer of $\operatorname{RBM}(\mathrm{s})$ ) of $\mathrm{DBN}$, we determine this parameter by using the embedding dimension $(m)$ that we obtained when applying the phrase-space reconstruction for each chaotic time series. That means the number of input nodes of the DBN model is the same as that of RBF network with 
chaos theory (RBF-2) for each dataset. As for the number units in hidden layer of RBM and the number of units in hidden layer of MLP and all the other remaining parameters, we have to determine them through experiment.

As for the CD-k algorithm to pre-train the DBN, we set the number of iterations $k$ to 2 .

Each dataset is divided into two sets: training set and test set. The training set and test set for each of the seven datasets are given in Table 3.

\section{Experimental Results}

The experimental results on prediction accuracy are reported in Table 4. The prediction errors of DBN model are shown in column 3 . The prediction errors of the two versions of RBF network method are shown in the columns 4 and 5.

From the experimental results in Table 4, we can see that the prediction errors MAE, MSE, MAPE of DBN method are always much lower than those of the two RBF methods in most of the tested datasets (5 out of 7). That means the DBN method achieves the best prediction accuracy for all seven datasets. However, for the USB/GBP dataset (length=295) and IBM dataset (length=255), DBN still brings out lower MAE and MSE errors, but has MAPE error a little bit higher than the two other methods. We conjecture that for these two times series datasets of small size, DBN cannot manifest its strength in comparison to RBF network, a shallow form of neural networks. This observation implies that deep neural networks, such as DBNs, can exhibit their superior performance especially in working with big data rather than small size data.

The training times (in milliseconds) of the three methods over seven datasets are given in Table 5 . From Table 5, we can see that the training time of DBN is much higher than those of the two versions of $\mathrm{RBF}$ method in most of the datasets.

\section{DISCUSSION}

In all experimented time series, RBF-2 model shows better prediction performance than RBF-1 model. This implies that by applying chaos theory (namely, phase-space reconstruction), RBF-2 model outperforms RBF-1 model which does not use chaos theory in chaotic time series prediction.

It should be noted that in this work the parameters of RBF networks (RBF1, RBF2) and the hyperparameters of DBN model are selected only after a few trial-and-error tests on a limited number of parameter values. As for DBN model, some previous works pointed out that its hyper-parameters, such as learning rate of RBM, the number of hidden units for MLP, learning rate of MLP, etc. have a great influence on the performance of this deep learning model $\left({ }^{9}\right)$. Therefore, the hyper-parameters of DBN model should be fine-tuned to its optimum before it can be used. One of the methods to handle this problem is applying some meta-heuristics to find suitable values of hyper-parameters in DBNs for forecasting time series.

\section{CONCLUSIONS}

In this paper, we present and evaluate extensively a method using DBN in phase-space prediction of chaotic time series. We compare the performance of DBN with that of RBF network in three synthetic datasets and four real world datasets of chaotic time series. Experimental results obtained reveal that the DBN method performs better than the RBF network, a shallow form of neural networks, in most of the datasets. Experimental results also show that deep neural networks, such as DBNs, can exhibit their superior performance especially in working with big data rather than small size data.

As for future work, we intend to apply some metaheuristics such as Particle Swarm Optimization (PSO) or Harmony Search in finding suitable values of hyper-parameters in DBNs for forecasting chaotic time series.

\section{LIST OF ABBREVIATION USED}

MPL: Multi-Layer Perceptron

DBN: Deep Belief Network

SVM: Support vector machine

RBF: Radial Basis Function

PSO: Particle Swarm Optimization

MAE: Mean absolute error

MSE: Mean squared error

MAPE: Mean absolute percentage error

CD: Contrastive Divergence

USD: United States Dollar

GBP: General British Pound

CPI: Consumer Price Index

IBM: IBM Stock Prices

\section{COMPETING ENTEREST}

The authors have declared that no competing interests exist.

\section{AUTHOR CONTRIBUTION}

Duong Tuan Anh has proposed the main ideas of the article, collected the datasets and wrote the article. Ta Ngoc Huy Nam has implemented the comparative models, conducted the experiments and reported the experimental results. 


\begin{tabular}{|c|c|c|}
\hline Dataset & RBF-1 & RBF-2 \\
\hline Lorenz & $\begin{array}{l}(5-5-0) \\
\text { Error threshold: } 0.001 \\
\eta_{3}: 0.1, \eta_{2}: 0.00001, \eta_{1}: 0.9\end{array}$ & $\begin{array}{l}(10-10-1) \\
\text { Error threshold: } 0.001 \\
\eta_{3}: 0.015, \eta_{2}: 0.00002, \eta_{1}: 0.015 \\
\text { Time delay } \mathrm{t}: 7\end{array}$ \\
\hline Mackey-Glass & $\begin{array}{l}(10-10-1) \\
\text { Error threshold: } 0.001 \\
\eta_{3}: 0.0025, \eta_{2}: 0.0002, \eta_{1}: 0.025\end{array}$ & $\begin{array}{l}(10-10-1) \\
\text { Error threshold: } 0.001 \\
\eta_{3}: 0.2, \eta_{2}: 0.3, \eta_{1}: 0.3 \\
\text { Time delay t: } 17\end{array}$ \\
\hline Rossler & $\begin{array}{l}(10-10-1) \\
\text { Error threshold: } 0.001 \\
\eta_{3}: 0.02, \eta_{2}: 0.0001, \eta_{1}: 0.1\end{array}$ & $\begin{array}{l}(10-10-1) \\
\text { Error threshold: } 0.001 \\
\eta_{3}: 0.04, \eta_{2}: 0.02, \eta_{1}: 0.01 \\
\text { Time delay } \mathrm{t}: 15\end{array}$ \\
\hline Sunspots & $\begin{array}{l}(4-4-1) \\
\text { Error threshold: } 0.001 \\
\eta_{3}: 0.001, \eta_{2}: 0.001, \eta_{1}: 0.002\end{array}$ & $\begin{array}{l}(5-5-1) \\
\text { Error threshold: } 0.0001 \\
\eta_{3}: 0.02, \eta_{2}: 0.001, \eta_{1}: 0.02 \\
\text { Time delay t: } 2\end{array}$ \\
\hline CPI & $\begin{array}{l}(2-2-1) \\
\text { Error threshold: } 0.0001 \\
\eta_{3}: 0.0045, \eta_{2}: 0.0035, \eta_{1}: 0.006\end{array}$ & $\begin{array}{l}(2-2-1) \\
\text { Error threshold: } 0.0001 \\
\eta_{3}: 0.004, \eta_{2}: 0.0048, \eta_{1}: 0.0065 \\
\text { Time delay t: } 77\end{array}$ \\
\hline USD/GBP & $\begin{array}{l}(4-4-1) \\
\text { Error threshold: } 0.0001 \\
\eta_{3}: 0.004, \eta_{2}: 0.003, \eta_{1}: 0.009\end{array}$ & $\begin{array}{l}(4-4-1) \\
\text { Error threshold: } 0.0001 \\
\eta_{3}: 0.04, \eta_{2}: 0.003, \eta_{1}: 0.01 \\
\text { Time delay t: } 17\end{array}$ \\
\hline IBM & $\begin{array}{l}(5-5-1) \\
\text { Error threshold: } 0.0001 \\
\eta_{3}: 0.004, \eta_{2}: 0.0001, \eta_{1}: 0.01\end{array}$ & $\begin{array}{l}(5-5-1) \\
\text { Error threshold: } 0.0001 \\
\eta_{3}: 0.045, \eta_{2}: 0.0001, \eta_{1}: 0.009 \\
\text { Time delay t: } 15\end{array}$ \\
\hline
\end{tabular}

\section{ACKNOWLEDGEMENT}

This research is funded by Vietnam National University Ho Chi Minh City (VNU-HCM) under grant number C2019-20-17.

\section{REFERENCES}

1. Takens F. Detecting strange attractors in turbulence, Dynamical Systems and Turbulence, Warwick 1980, London. Springer. 1981;p. 366-381. Available from: https://doi.org/10.1007/ BFb0091924.

2. Kennel MB, Brown R, Abarbanel HDI. Determining embedding dimension for phase-space reconstruction using a geometrical construction. PHYSICAL REVIEW A. 1992;45(6):34033411. PMID: 9907388. Available from: https://doi.org/10.1103/ PhysRevA.45.3403.

3. Hinton GE, Osindero S, Teh YW. A Fast Learnig Algorithm for Deep Belief Nets. Neural Computing. 2006;18:1527-1554. PMID: 16764513. Available from: https://doi.org/10.1162/neco. 2006.18.7.1527.

4. Chong E, Chang C, Park FC. Deep learning network for stock market analysis and prediction. Methodologies, Data Representation and Case studies, Expert Systems with Applications. 2017;83:87-205. Available from: https://doi.org/10.1016/j. eswa.2017.04.030.
5. Zheng J, Fu X, Zhang G. Research on exchange rate forecasting based on deep belief network, Neural Computing and Applications. Springer. 2017; Available from: https://doi.org/10. 1007/s00521-017-3039-z.

6. Li C, Bai Y, Zeng B. Deep learning architecture for daily reservoir inflow forecasting. Water Resource Management. 2016;30:5145-5161. Available from: https://doi.org/10.1007/ s11269-016-1474-8.

7. Cao TN, Duong HN, Tran HV, Snasel V. Predicting daily river runoff by deep belief networks. Proc of Int Conf on Information and Convergence Technology for Smart Society, Ho Chi Minh City. 2016;.

8. He W. Deep neural network based load forecast. Computing Modelling and New Technologies. 2014;18(3):258-262.

9. Kuremoto T, Obayashi M, Kobayashi K, Hirata T, Mabu S. Forecast Chaotic Time Series Data by DBNs, Proc. 7th Int. Congress on Image \& Signal Processing. 2014;Available from: https:// doi.org/10.1109/CISP.2014.7003950.

10. Truc NV, Anh DT. Chaotic Time Series Prediction Using Radial Basis Function Networks, Proc. of 4th Int. Conf. on Green Technology and Sustainable Development (GTSD2018), IEEE, November 23-24. HCMC Univ of Technology \& Education, Vietnam. 2018;p. 753-758. Available from: https://doi.org/10. 1109/GTSD.2018.8595677.

11. Fraser AM, Swinney HL. Independent Coordinates for Strange Attractors from Mutual Information. Physia D;33:1134-1986. PMID: 9896728. Available from: https://doi.org/10.1103/ 
Table 2: Parameters for DBN (RBM+MLP)

\begin{tabular}{ll}
\hline Dataset & DBN (RBM+MLP) \\
Lorenz & The max number of epochs for RBM: 100, Learning rate of RBM: 0.01, \\
& The max number of epochs for MLP: 1500, The number of hidden units for MLP: 5 \\
& Learning rate of MLP: 0.03 \\
Mackey-Glass & The max number of epochs for RBM: 100 , Learning rate of RBM: 0.01, \\
& The max number of epochs for MLP: 1500 , The number of hidden units for MLP: 10 \\
& Learning rate of MLP: 0.03 \\
Rossler & The max number of epochs for RBM: 20 , Learning rate of RBM: 0.01, \\
& The max number of epochs for MLP: 500 , The number of hidden units for MLP: 10 \\
Learning rate of MLP: 0.03 \\
The max number of epochs for RBM: 50 , Learning rate of RBM: 0.05, \\
The max number of epochs for MLP: 2500 , The number of hidden units for MLP: 5 \\
Learning rate of MLP: 0.008 \\
The max number of epochs for RBM: 150 , Learning rate of RBM: 0.01, \\
The max number of epochs for MLP: 1200 , The number of hidden units for MLP: 2 \\
Learning rate of MLP: 0.005 \\
TBM
\end{tabular}

Table 3: Training set and test set for each of 7 datasets

\begin{tabular}{llll}
\hline Dataset & Length & Training set & Test set \\
Lorenz & 1000 & 800 & 200 \\
Mackey-Glass & 1001 & 800 & 201 \\
Rossler & 8192 & 8000 & 192 \\
Sunspots & 305 & 288 & 17 \\
CPI & 535 & 481 & 54 \\
USD/GBP & 295 & 285 & 10 \\
IBM & 255 & 245 & 10 \\
\hline
\end{tabular}

PhysRevA.33.1134.

12. Rossenstein MT, Colins JJ, Luca CJ. Reconstruction expansion as a geometry-based framework for choosing proper delay times. Physica D. 1994;73(1):82-98. Available from: https: //doi.org/10.1016/0167-2789(94)90226-7.
13. Verleysen M, Hlavackova K. Learning in RBF Networks. Proc of Int Conf on Neural Networks (ICNN). 1996;p. 199-204.

14. Pattanayak S. Pro Deep Learning with Tensorflow. Apress. 2017;Available from: https://doi.org/10.1007/978-1-48423096-1. 


\begin{tabular}{|c|c|c|c|c|}
\hline Dataset & & DBN & RBF-1 & RBF-2 \\
\hline \multirow[t]{3}{*}{ Lorenz } & MAE & 0.012 & 4.15 & 1.18 \\
\hline & MSE & 0.000002 & 20.32 & 2.51 \\
\hline & MAPE & $0.47 \%$ & $45.4^{c} \%$ & $18.35 \%$ \\
\hline \multirow{3}{*}{ Mackey- } & MAE & 0.0047 & 0.14 & 0.01 \\
\hline & MSE & 0.000035 & 0.03 & 0.013 \\
\hline & MAPE & $0.78 \%$ & $16.43 \%$ & $11.89 \%$ \\
\hline \multirow[t]{3}{*}{ Rossler } & MAE & 0.000112 & 3.63 & 1.94 \\
\hline & MSE & 0.000006 & 17.52 & 6.42 \\
\hline & MAPE & $0.35 \%$ & $137.17 \%$ & $51 \%$ \\
\hline \multirow[t]{3}{*}{ Sunspots } & MAE & 0.0392 & 33.80 & 10.82 \\
\hline & MSE & 0.0026 & 1843.37 & 150.61 \\
\hline & MAPE & $18.69 \%$ & $72.27 \%$ & $20.49 \%$ \\
\hline \multirow[t]{3}{*}{ CPI } & MAE & 0.0047 & 2.13 & 1.84 \\
\hline & MSE & 0.000036 & 5.49 & 4.46 \\
\hline & MAPE & $0.52 \%$ & $1.91 \%$ & $1.66 \%$ \\
\hline \multirow[t]{3}{*}{ USD/GBP } & MAE & 0.0023 & 0.15 & 0.01 \\
\hline & MSE & 0.00018 & 0.00027 & 0.0003 \\
\hline & MAPE & $4.87 \%$ & $2.12 \%$ & $1.59 \%$ \\
\hline \multirow[t]{3}{*}{ IBM } & MAE & 0.03 & 14.35 & 5.49 \\
\hline & MSE & 0.001608 & 257.647 & 41.46 \\
\hline & MAPE & $3.51 \%$ & $2.49 \%$ & $1.06 \%$ \\
\hline
\end{tabular}

Table 5: Training time of the three methods on $\mathbf{7}$ datasets

\begin{tabular}{llll}
\hline Dataset & DBN & RBF-1 & RBF-2 \\
Lorenz & 513000 & 133 & 4905 \\
Mackey-Glass & 151000 & 362 & 191 \\
Rossler & 395000 & 362 & 191 \\
Sunspots & 66500 & 1028 & 3363 \\
CPI & 122000 & 336 & 2189 \\
USD/GBP & 184000 & 36 & 57 \\
IBM & 219000 & 637 & 534 \\
\hline
\end{tabular}




\title{
Dự báo dữ liệu chuỗi thời gian có tính hỗn loạn dựa vào mạng deep belief network: một đánh giá thực nghiệm
}

\author{
Tạ Ngọc Huy Nam, Dương Tuấn Anh*
}

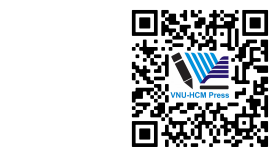

Use your smartphone to scan this QR code and download this article

\section{TÓM TẮT}

Dữ liệu chuỗi thời gian có tính hỗn loạn xuất hiện nhiều trong các lãnh vực ứng dụng thực tế như tài chính, môi trường, khí tượng thủy văn, giao thông, thời tiết.v.v. Chuỗi thời gian có tính hỗn loạn được xem như sinh ra từ chuyển động tất định của một hệ thống phi tuyến. Một hệ thống có tính hỗn loạn thường nhạy cảm với những điều kiện ban đầu: những điểm mà ngẫu nhiên ban đầu gần nhau lại trở nên cách xa nhau với mức độ tăng hàm mũ theo thời gian. Do đó dự báo dữ liệu chuỗi thời gian có tính hỗn loạn là một công tác đây thách thức. Công tác dự báo sử dụng các kỹ thuật thống kê truyên thống, giải thuật k-lân cận gần nhất, mạng perceptron đa tầng (MPL), mạng nơ ron hồi quy, mạng hàm căn bản xuyên tâm (Radial-Basis-Function-RBF) và máy vector hỗ trợ, thường không đem lại kết quả dự báo đáng tin cậy đối với chuỗi thời gian có tính hỗn loạn. Trong bài báo này, chúng tồi khảo sát bằng thực nghiệm việc dự báo dữ liệu chuỗi thời gian có tính hỗn loạn bằng cách kết hợp mạng nơ ron học sấu Deep Belief Network (DBN) với lý thuyết hỗn loạn. Mạng nơ ron DBN nên được dùng để dự báo chuỗi thời gian có tính hỗn loạn. Đẩu tiên, chuỗi thời gian có tính hỗn loạn được phân tích bằng cách tính số mũ Lyapunov cực đại, tái cấu trúc chuỗi thời gian dựa vào xây dựng không gian pha và xác định số chiều nhúng và độ trễ thời gian tốt nhất. Chúng tôi so sánh phương pháp đề xuất với mạng nơ ron RBF, một phương pháp hiệu quả để dự báo dữ liệu chuỗi thời gian có tính hỗn loạn. Chẩt lượng dự báo của hai mô hình được khảo sát dựa vào các tiêu chí đánh giá: sai số tuyệt đối trung bình (MAE), sai số bình phương trung bình (MSE) và sai số phần tram tuyệt đối trung bình (MAPE). Kết quả thực nghiệm trên nhiều bộ dữ liệu chuỗi thời gian tổng hợp và chuỗi thời gian thực tế có tính hỗn loạn cho thấy phương pháp sử dụng mạng Deep Belief Network hữu dụng cho việc dự báo dữ chuối thời gian có tính hỗn loạn vì phương pháp đem lại độ chính xác dự báo cao hơn mạng nơ ron RBF.

Từ khoá: Mạng Deep Belief Network, Máy Boltzmann Giới Hạn, chuỗi thời gian có tính hỗn loạn, mạng RBF, dự báo
Truờng Đại học Bách Khoa,

DHQG-HCM

Liên hệ

Dương Tuấn Anh, Trường Đại học Bách

Khoa, ĐHQG-HCM

Email: dtanhcse@gmail.com

Lịch sử

- Ngày nhận: 28-8-2019

- Ngày chấp nhận: 26-9-2019

- Ngày đăng: 04-12-2020

DOI :10.32508/stdjet.v3iS11.571

\section{Check for updates}

\section{Bản quyền}

๑ ĐHQG Tp.HCM. Đây là bài báo công bố mở được phát hành theo các điều khoản của the Creative Commons Attribution 4.0

International license.

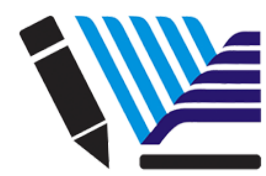

VNU-HCM Press
Trích dẫn bài báo này: Nam T N H, Anh D T. Dự báo dữ liẹu chuỗi thời gian có tính hỗn loạn dưa vào mạng deep belief network: một đánh giá thực nghiệm. Sci. Tech. Dev. J. - Eng. Tech.; 3(SI1):SI102SI112. 